\title{
Information Technology Behavior Cyberbullying in Thailand: Incidence and Predictors of Victimization and Cyber-Victimization
}

\author{
Ruthaychonnee Sittichai ${ }^{1}$ \\ ${ }^{1}$ Faculty of Humanities and Social Sciences, Prince of Songkla University, Pattani, Thailand \\ Correspondence: Ruthaychonnee Sittichai, Faculty of Humanities and Social Sciences, Prince of Songkla \\ University, Pattani, Thailand. E-mail: ruthsittichai@gmail.com
}

Received: January 16, 2014 Accepted: April 9, 2014 Online Published: May 30, 2014

doi:10.5539/ass.v10n11p132 URL: http://dx.doi.org/10.5539/ass.v10n11p132

\begin{abstract}
Cyberbullying is becoming an important issue internationally, including in Thailand. I report findings from a questionnaire survey of 1,183 students drawn from 12 schools in southern Thailand, aged 14 to 17 years. The questions asked included demographic information, use of ICT, as well as experiences of being a victim or perpetrator of traditional bullying (not cyber) and cyberbullying. Students were asked if they had been bullied (not cyber), or cyberbullied at school in the past couple of months. We used two criteria of involvement: lenient (it happened at least once or twice), and strict (it happened 2 or 3 times a month or more). With the lenient criterion, $16.0 \%$ were traditional victims and $14.9 \%$ cybervictims. With the strict criterion, $6.0 \%$ were traditional victims and $3.7 \%$ cybervictims. We carried out logistic regression analyses in order to see how victim status was predicted, on the basis of 5 variables: gender, grade, religion, province, and parent education. Separate analyses were carried out, for lenient and severe criteria, and for traditional and cyber victim. Three criteria were non-significant for all four of these analyses: grade, province, and religion. Gender was significant in all analyses: male students were more likely to be victims, especially cyber victims. Parent education was significant, but only for lenient cybervictims: here, higher parental education was associated with greater risk of being a victim. The findings are discussed in relation to research in other eastern and western cultures; and to the needs for further research and intervention in schools in Thailand.
\end{abstract}

Keywords: cyberbullying, victimization, Thailand, information technology behavior

\section{Introduction}

Bullying has been defined by Olweus as an aggressive act that is also characterized by repetition and am imbalance of power (Olweus, 1993). These latter two criteria distinguish bullying from other kinds of aggressive behaviour. Bullying is an important problem in schools. It has been shown to seriously affect the health and well-being of victims, with suicide occurring in some instances. Those doing the bullying are starting on what may be a long-term path of antisocial behavior, while for bystanders and the school generally this can lead to poor morale and poorer school climate, especially if bullying is frequent and not dealt with properly. There is now high awareness of this in most European countries, and programs to prevent school bullying have been devised. Some interventions, such as the Olweus Bullying Prevention Program, and KiVA, have had considerable and replicated success (Smith, Pepler \& Rigby, 2004; Ttofi \& Farrington, 2011).

Cyberbullying refers to bullying of others by means of mobile phones and the internet. Following from a long tradition of research on traditional (or offline) bullying in schools, the study of cyberbullying (or online bullying) has increased in the last decade. Reports of cyberbullying first just involved abusive or threatening text messages on mobile phones, or emails. However over the last decade forms of cyberbullying have diversified to instant messaging, chat rooms, and social networking sites, following the development of these technologies and their penetration amongst young people. Smith et al. (2008: 236) have defined cyberbullying as: "An aggressive, intentional act carried out by a group or individual, using electronic forms of contact, repeatedly and over time against a victim who cannot easily defend him or herself", following the Olweus definition of traditional bullying.

Cyberbullying is an important phenomenon in its own right, and it has added a new dimension to the study of bullying. It has a number of distinctive features in the way it is carried out, how it is experienced and the kinds of impact it has. Unlike offline bullying, online or cyberbullying has the potential to grow with the increasing use 
of laptop computers, tablets, and smart phones, and the growth of virtual social networks. Researchers, teachers, parents, and young people themselves, are often struggling with these issues, as are educational authorities and mobile phone companies and, internet service providers.

Types of cyberbullying

There is debate about whether cyberbullying can be considered as a single construct, or is best considered as different types. Some aspects of cyberbullying, including gender differences, and the impact it has, do vary by the type of cyberbullying experienced - for example, contrasting Internet and mobile phone bullying (Ortega, Elipe, Mora-Merchan, Calmaestra \& Vega, 2009). But the advent of smart phones in the last few years makes this distinction, useful at the time, now rather problematic.

Age and gender

In a review of studies a few years ago, Tokunaga (2010) found a curvilinear relationship for cyber victimization with age, this being highest at around 13-15 years. Of course cyberbullying is also found amongst adults, but Ševciková and Šmahel (2009) found that after adolescence it declines considerably in incidence.

Findings concerning gender differences are very varied: indeed Tokunaga $(2010, p .280)$ described this area "fraught with inconsistent findings". Somre studies reported boys as being more involved than girls (e.g., Calvete, Orue, Estévez, Villardón, \& Padilla, 2010; Fanti, Demetriou \& Hawa, 2012; Salmivalli \& Pöyhönen, 2012). Some studies find little gender difference (e.g., Smith et al., 2008; Livingstone, Haddon, Görzing \& Ólafsson, 2011). Some studies even find girls more involved than boys (e.g., Rivers \& Noret, 2010). Smith (2012) argued that notwithstanding these different findings, it was possible to generalize that compared to traditional physical or verbal bullying, girls were relatively more involved in cyberbullying, just as they tend to be relational bullying. The varying findings reported for gender differences may be explicable in terms of sample variations, different definitions used, and the types of cyberbullying assessed. Historical changes even over a year or so can be important too; the last few years have seen increased use of social networking, in girls especially; Patchin \& Hinduja, 2010).

\section{Overlap with traditional bullying}

There is a large overlap between involvement in traditional bullying and cyberbullying. This has been found in many studies, and is true both for bully role and victim role (e.g. Raskauskas \& Stoltz, 2007; Smith et al., 2008; Livingstone et al., 2011; Salmivalli \& Pöyhönen, 2012).

\section{Research in different cultures}

Cyberbullying research has grown very rapidly in the last decade. Nevertheless, the vast majority of studies have been carried out in western cultures, especially Europe, North America, and Australia. There has been a more limited number of sudies in Japan, South Korea and China (Li, Cross \& Smith, 2012). In contrast, there has been little research in south-east Asian countries. Reviewing studies of bullying and cyberbullying in Thailand, Sittichai and Smith (2013) noted the relatively small number of reports, especially of cyberebullying, and also significant limitations in many of them; of eight relevant reports, only three explicitly discussed cyberbullying. The reports were mainly qualitative, and did not consistently distinguish (cyber) bullying from general aggression. Nevertheless many young people in Thailand use mobile phones and the internet. Out of a population over 67 million, some 26 percent have at least one mobile phone, over 31 percent have easy internet/ICT access, and over 25 percent are Facebook subscribers. (Statistics for 30 June, 2012, from http://www.internetworldstats.com/stats3; http://www.nationmaster.com/graph/med_mob_pho-media-mobile-pho nes).

The Objectives of this study are to investigate the prevalence of being a victim of both traditional bullying (not cyber), and cyberbullying, among school students in Southern Thailand and to examine the impact of various demographic variables and ICT use on the likelihood of being a traditional or cyber victim.

\section{Method}

\subsection{The Study Area / Target Group}

Population: Students in Southern Thailand.

Sample: The samples were selected by simple random sampling method, with an initial sample of 1,200 students in the secondary and high schools of 3 provinces: Pattani, Yala, and Narathiwat.

\section{Research Tool}

The questionnaire was adapted from one used in the UK (Smith, 2008); paper copies were used for data 
collection. The questionnaire covered demographic information, ICT use, and experiences of being a victim of traditional bullying (not cyber) and of cyberbullying.

Variables

Independent variables: Gender, Grade, Religion, Province, Parent education

Grade was grouped in to 4 levels: grades 7-8, 9, 10, and 11-12. There were 2 religious groups: Buddhists and Muslim. The students were from 3 provinces as stated above. Parent education was classified into 3 groups, high (BA, MA, and higher degree), medium (High school), and low (Primary school).

Dependent Variables:

Students were asked if they had been bullied (not cyber), or cyberbullied at school in the past couple of months, on a standard 5-point scale. Students reported being victimized (traditional or cyber) as either never, just once or twice, two or three times a month, once a week, or several times a week. Victimization was then categorized using either a Lenient or Strict criterion regarding self-reported frequency. Lenient Traditional Victimization was scored if someone reported getting bullied in this way, once or twice, or more, in the past couple of months. Strict Traditional Victimization was scored if someone reported getting bullied in this way two or three times a month or more, in the past couple of months. Lenient Cybervictimization was scored if someone reported getting cyberbullied once or twice or more, in the past couple of months. Strict Cybervictimization was scored if someone reported getting cyberbullied two or three times a month or more, in the past couple of months.

\subsection{Data Collection}

Data was collected from 12 secondary and high schools in the 3 provinces of southern Thailand. Pupils were mainly aged 14 to 17 years. Altogether 1,200 students contributed data; 400 students from each province. After screening, valid responses were obtained from 1,183 students.

The researcher and a research assistant went to the schools to collect the data, giving out questionnaires on a class basis. Data was gathered during March 2012.

\subsection{Data Analysis}

Multiple logistic regression analysis is used for modeling the association between several determinant variables and bullying cyber victimization. Logistic regression is a method of analysis that gives a particularly simple presentation for the logarithm of the odds ratio describing the association of a binary outcome with factors, and when fitted to data involving a dichotomous outcome and multiple determinants, it automatically provides estimates of odds ratios and confidence intervals for specific combinations of the risk factor (McNeil, 1998).

\section{Results}

First the analysis for the personal characteristics of the sample, and the number and percentage of victims and cyber victim on both lenient and strict criterion, is reported. In the descriptive analysis part all 1,200 of the sample were shown. Then a cross-tabulation for gender and logistic regression for the predictors (gender, province, grade, religion and parent education) of the data is presented.

Of the 1,200 students 57\% are female and $43 \%$ male. Most of them are Muslim. The province that most of them come from is Pattani followed by Narathiwat and Yala respectively. 30.3\% of the students are from grades 11 and 12 , followed by grade 9 , grade 7 and 8 and grade 10 . Half of the parents have medium education which is high school level. $86 \%$ owned a mobile phone (for about half, this was a smart phone), $86 \%$ had been online, with $60 \%$ having access to the internet at home. Over half of them access into the internet from $0-5$ hour(s), followed by $5-10$ hours and $10-15$ hours per week; only $6 \%$ of them access into the internet 20 hours or more per week. 
Table 1. The number and percentage of the traditional lenient victims and cyber lenient victims

\begin{tabular}{ccc}
\hline Traditional Lenient Victims & Frequency & Percentage \\
\hline Non Victim & 994 & 84.0 \\
Lenient Victim & 190 & 16.0 \\
Total & 1,184 & 100.0 \\
Cyber Lenient Victims & & \\
Non Cyber Victim & 1,007 & 85.1 \\
Lenient Cyber Victim & 176 & 14.9 \\
Total & 1,183 & 100.0 \\
\hline
\end{tabular}

On the lenient criterion, $16.0 \%$ were traditional victims and $14.9 \%$ were cyber-victims.

Table 2. The number and percentage of the traditional strict victims and cyber strict victims

\begin{tabular}{ccc}
\hline Traditional Strict Victims & Frequency & Percentage \\
\hline Non Victim & 1,113 & 94.0 \\
Strict Victim & 71 & 6.0 \\
Total & 1,184 & 100.0 \\
Cyber Strict Victims & & \\
Non Cyber-Victim & 1,139 & 96.3 \\
Lenient Cyber-Victim & 44 & 3.7 \\
Total & 1,183 & 100.0 \\
\hline
\end{tabular}

On the strict criterion, $6.0 \%$ were traditional victims and $3.7 \%$ were cybervictims.

Incidence and gender differences

Male students were more likely to be victims, in each case, although this was more marked for the strict criterion, and for being a cyber victim than a traditional victim.

Table 3. The cross tabulation between gender and traditional lenient victims

\begin{tabular}{cccc}
\hline Gender & \multicolumn{2}{c}{ Traditional Lenient Victim } & Total \\
& Non-Lenient Victim & Lenient Victim & \\
\hline Male & 409 & 95 & 504 \\
Female & 583 & 94 & 677 \\
Total & 992 & 189 & 1,181 \\
\hline
\end{tabular}

Table 4. The cross tabulation between gender and traditional strict victims

\begin{tabular}{cccc}
\hline Gender & \multicolumn{2}{c}{ Traditional Strict Victim } & Total \\
& Non-Strict Victim & Strict Victim & \\
\hline Male & 461 & 43 & 504 \\
Female & 650 & 27 & 677 \\
Total & 1,111 & 70 & 1,181 \\
\hline
\end{tabular}


Table 5. The cross tabulation between gender and cyber lenient victims

\begin{tabular}{cccc}
\hline \multirow{2}{*}{ Gender } & \multicolumn{2}{c}{ Cyber Lenient Victim } & Total \\
& Non cyber Lenient Victim & Cyber Lenient Victim & \\
\hline Male & 412 & 93 & 505 \\
Female & 593 & 82 & 675 \\
Total & 1,005 & 175 & 1,180 \\
\hline
\end{tabular}

Table 6. The cross tabulation between gender and cyber strict victims

\begin{tabular}{cccc}
\hline Gender & \multicolumn{2}{c}{ Cyber Strict Victim } & Total \\
& Non cyber Strict Victim & Cyber Strict Victim & \\
\hline Male & 475 & 30 & 505 \\
Female & 661 & 14 & 675 \\
Total & 1,136 & 44 & 1180 \\
\hline
\end{tabular}

Overlap of traditional with cyber bullying

Table 7. The cross tabulation between traditional lenient victims and cyber lenient victims

\begin{tabular}{cccc}
\hline Traditional & \multicolumn{2}{c}{ Cyber Lenient Victim } & Total \\
Victim & Non cyber Lenient Victim & Cyber Lenient Victim & \\
\hline Non Victim & 901 & 86 & 987 \\
Strict Victim & 100 & 88 & 188 \\
Total & 1,001 & 174 & 1,175 \\
\hline
\end{tabular}

On the lenient criterion, the traditional victims were more likely to be cyber victims.

Table 8 . The cross tabulation between traditional strict victims and cyber strict victims

\begin{tabular}{cccc}
\hline $\begin{array}{c}\text { Traditional } \\
\text { Victim }\end{array}$ & Non cyber Strict Victim & Cyber Strict Victim & Total \\
\hline Non Victim & 1,081 & 24 & \\
Strict Victim & 50 & 20 & 1,105 \\
Total & 1,131 & 44 & 70 \\
\hline
\end{tabular}

On the strict criterion, the traditional victims were more likely to be cyber victims.

In summary, on both criteria, about half of the cyber-victims were also traditional victims.

Logistic regression analyses

Logistic regression analyses were carried out to predict victim status from 5 variables: gender (2), grade (4 levels; Grade 7- 8; 9; 10; and 10-11), religion (Buddhist, Muslim), province (3) and parent education (3 levels). Four analyses were carried out, for Victim Lenient (VictimL) Cyber Victim Lenient (CyberVictimL), Victim Strict (VictimS) and Cybervictim Strict (CyberVictimS). Grade, religion, and province were non-significant in all four analyses. 
Table 9. Predictors of victim status

Logistic Regression for Lenient Victimization

\begin{tabular}{lccccc}
\hline Predictors & B & S.E. & df & Sig. & Exp(B) \\
\hline Province & .128 & .098 & 1 & .195 & 1.136 \\
Grade & -.010 & .072 & 1 & .886 & .990 \\
Religion & -.014 & .177 & 1 & .936 & .986 \\
Parent Education & -.018 & .126 & 1 & .887 & .982 \\
Gender & -.334 & .165 & 1 & .043 & .716 \\
Constant & -1.315 & .605 & 1 & $.030^{*}$ & .269 \\
\hline
\end{tabular}

Logistic Regression for Lenient Cyber-Victimization

\begin{tabular}{cccccc}
\hline Predictors & B & S.E. & df & Sig. & Exp(B) \\
\hline Province & .189 & .103 & 1 & .067 & 1.209 \\
Grade & .070 & .076 & 1 & .353 & 1.073 \\
Religion & -.076 & .183 & 1 & .676 & .926 \\
Parent Education & .347 & .136 & 1 & $.011^{*}$ & 1.414 \\
Gender & -.497 & .172 & 1 & $.004^{*}$ & .609 \\
Constant & -2.236 & .642 & 1 & .000 & .107 \\
\hline
\end{tabular}

Logistic Regression for Strict Victimization

\begin{tabular}{lccccc}
\hline Predictors & B & S.E. & df & Sig. & Exp(B) \\
\hline Province & -.008 & .153 & 1 & .958 & .992 \\
Grade & -.074 & .114 & 1 & .515 & .929 \\
Religion & .083 & .286 & 1 & .773 & 1.086 \\
Parent Education & -.208 & .197 & 1 & .292 & .813 \\
Gender & -.835 & .266 & 1 & $.002^{*}$ & .434 \\
Constant & -1.050 & .937 & 1 & .262 & .350 \\
\hline
\end{tabular}

Logistic Regression for Strict Cyber-Victimization

\begin{tabular}{lccccc}
\hline Predictors & B & S.E. & df & Sig. & Exp(B) \\
\hline Province & .032 & .197 & 1 & .869 & 1.033 \\
Grade & -.083 & .147 & 1 & .572 & .920 \\
Religion & -.223 & .348 & 1 & .522 & .800 \\
Parent Education & -.015 & .259 & 1 & .955 & .985 \\
Gender & -.982 & .350 & 1 & $.005^{*}$ & .375 \\
Constant & -1.373 & 1.197 & 1 & .251 & .253 \\
\hline
\end{tabular}

Gender was significant in all four analyses (males higher). Parent's education was significant, but only for lenient cybervictims: higher parental education as associated with greater victim risk.

\section{Discussion and Conclusions}

The prevalence rates for traditional and cyber victimization were found to be about $6 \%$ and $3.7 \%$ on a strict criterion, and $16 \%$ and $15 \%$ on a more lenient criterion.

These figures are fairly similar to those found in many western countries. For example, the EU Kids Online survey (Livingstone et al., 2011), carried out in 2010, found that across 25 European countries, experiences of being a victim was about $9 \%$ on a stricter criterion and $19 \%$ on a more lenient criterion (using similar criteria to those employed in this study). Taking the more lenient criterion, $13 \%$ reported being bullied face-to-face or offline, and $6 \%$ on the internet (mostly on a social networking site or by instant messaging), and $3 \%$ from using 
mobile phone.

Although the overall prevalence of bullying is not so different, there does seem to be a relatively high ratio of cyber to traditional victimization in southern Thailand. In western countries, cyber-victimization rates are often about one-third of traditional victimization (Smith, 2010; Livingstone et al., 2011), but currently in southern Thailand, there is a relatively higher proportion of cyber victims relative to traditional victims. Clearly cyberbullying is an important issue to be addressed among young people in Thailand.

There was a significant overlap between being a cyber-victim and being a traditional victim. This is in line with many studies from western cultures. Nevertheless, in this sample about half of all cyber-victims were not traditionally bullied, which is quite a high proportion in comparison to other studies (Smith, 2012). Again this suggests the importance of cyber-victimization in the Thai context.

Gender was significant in all four analyses, with males higher, especially for cyberbullying. As noted in the literature review, gender differences in cyberbullying have been very varied in western studies, but it appears relatively unusual to find a male prevalence for victims higher for cyber than for traditional bullying. This might be a clue as to why being a cyber victim takes up a relatively high proportion of all victim experiences, in this sample.

To investigate this further, gender differences in ICT use were examined from the questionnaire data. The higher rate of cyber victimization in males was not due to frequency of ICT use, as this if anything higher in females. However male students did spend more time surfing the net, and playing games, which might provide more opportunities for cyberbullying; female students spent more time using the internet for schoolwork, and also on facebook.

Grade, religion, and province were non-significant in all four analyses. The grade levels were relatively restricted (about 14 to 17 years), and age/grade could be expected to be more significant with a wider age range.

Parent's education was significant, but only for lenient cybervictims: higher parental education as associated with greater victim risk. Follow-up analyses suggest that this was partly accounted for by students with more highly educated parents having greater access to the internet at home, and being more likely to have a smart phone. Thus, this find may be due to opportunistic factors; these students from highly educated parents were more likely to experience cyberbullying once or twice, but were not at greater risk of severe victimization.

Some limitations to the study should be noted. First, the sample, while quite large, may lack power when sub-dividing by age, gender, and other factors such as ICT use. Second, other possible or likely predictive factors were not examined in this study; for example, parenting style, and parent-child relationships. Finally, predictive factors may vary by different types of cyber-victimization, which should be studied more in further research.

I conclude that Victimization experiences in this sample of secondary school students from southern Thailand are at a comparable level to that found in western studies. Furthermore, the relative proportion of cyber-victimization, and the proportion of male involvement in this, appears higher than in many western studies. Further research is needed to replicate these trends in a larger sample, and to look more at different types of cyber-victimization. The findings of this and future studies can feed into efforts to educate teachers, parents, and young people, to reduce effects of bullying and cyberbullying, as has been done with some success in some European countries, North America, and Australia.

There are many programs devised for traditional bullying, which as Ttofi and Farrington (2011) have shown, often have reasonable success rates. Some aspects of these can be extended to include cyberbullying without major changes; clearly cyberbullying needs to be incorporated in components of these programs, such as a whole-school anti-bullying policy, and awareness-raising and curriculum-based activities. An example of a successful general anti-bullying program is the KiVa program in Finland, which includes computer based classroom activities, and support for victims from high-status peers. Although primarily designed with traditional bullying in mind, evaluations so far show that KiVa is as effective in reducing cyberbullying as it is for a range of traditional forms (Salmivalli, Kärna, \& Poskiparta, 2011).

In addition new technical developments may help. A U.K. charity, Beatbullying, launched a new form of virtual peer support called CyberMentors in 2009. Students are trained as cybermentors, log on and mentor on demand. Cybermentors can refer mentees on to senior cybermentors and counselors for further support if necessary. This scheme has been evaluated quite positively by Banerjee, Robinson and Smalley (2010) and Thompson and Smith (2011). Not many intervention or prevention programs exist that deal specifically with cyberbullying; a Campbell review by Mishna, Cook, Saini, Wu, and MacFadden (2009) documented four short-term programs, that had had little effect. However resources are being developed, for example, in England, Thompson, Robinson 
and Smith (2013) evaluated two e-safety films used by secondary schools, Childnet International's Let's Fight It Together about cyberbullying and Child Exploitation and Online Protection's (CEOP) Exposed, about sexting. Both films and resources were rated as good by pupils and staff.

In summary, cybervictimization as well as traditional victimization is an important issue in Thai schools. Experience in western countries may be useful for considering and adapting intervention procedures in the Thai context.

\section{Acknowledgements}

I would like to express my gratitude and deep appreciation to my research mentor, Professor Peter K Smith. I would also like to thank the Dean, Associate Professor Awang Lanui, who approved an HUSO Grant of Faculty of Humanities and Social Sciences, Research Development Office Prince of Songkla University, Thailand for funding and supporting my research.

\section{References}

Banerjee, R., Robinson, C., \& Smalley, D. (2010). Evaluation of the Beatbullying Peer Mentoring Programme. Report for Beatbullying. University of Sussex.

Calvete, E., Orue, I., Estévez, A., Villardón, L., \& Padilla, P. (2010). Cyberbullying in adolescents: Modalities and aggressors' profile. Computers in Human Behavior, 26, 1128-1135. http://dx.doi.org/10.1016/j.chb.2010.03.017

Fanti, K. A., Demetriou, A. G., \& Hawa, V. V. (2012). A longitudinal study of cyberbullying: Examining risk and protective factors. European Journal of Developmental Psychology, 9, 168-181. http://dx.doi.org/10.1080/17405629.2011.643169

Li, Q., Cross, D. \& Smith, P. K. (Eds.). (2012). Cyberbullying in the Global Playground: Research from International Perspectives. Chichester: Wiley-Blackwell. http://dx.doi.org/10.1002/9781119954484

Livingstone, S., Haddon, L., Görzig, A., \& Ólafsson, K. (2011). Risks and safety on the internet: The perspective of European children. Full findings. LSE, London: EU Kids Online.

McNeil, D. (1998). Modern statistics: A graphical introduction. Sydney, Australia: Macquarie University.

Mishna, F., Cook, C., Saini, M., Wu, M.-J., \& MacFadden, R. (2009). Interventions for children, youth and parents to prevent and reduce cyber abuse. Oslo, Norway: Campbell Systematic Reviews.

Olewus, D. (1993). Bullying at school: What we know and what we can do? Malden, MA: Blackwell.

Ortega, R., Elipe, P., Mora-Merchan, J. A., Calmaestra, J., \& Vega, E. (2009). The emotional impact on victims of traditional bullying and cyberbullying: A study of Spanish adolescents. Zeitschrift für Psychologie/Journal of Psychology, 217(4), 197-204. http://dx.doi.org/10.1027/0044-3409.217.4.197

Patchin, J. W., \& Hinduja, S. (2010). Trends in online social networking: adolescent use of MySpace over time. New Media and Society, 12, 197-216. http://dx.doi.org/10.1177/1461444809341857

Raskauskas, J., \& Stoltz, A. D. (2007). Involvement in traditional and electronic bullying among adolescents. Developmental Psychology, 43, 564-575. http://dx.doi.org/10.1037/0012-1649.43.3.564

Rivers, I., \& Noret, N. (2010). 'I h8 u': findings from a five-year study of text and email bullying. British Educational Research Journal, 36, 643-671. http://dx.doi.org/10.1080/01411920903071918

Salmivalli, C., \& Pöyhönen, V. (2012). Cyberbullying in Finland. In Q. Li, D. Cross \& P. K. Smith (Eds.), Cyberbullying in the Global Playground: Research from International Perspectives (pp. 57-72). Chichester: Wiley-Blackwell. http://dx.doi.org/10.1002/9781119954484.ch4

Salmivalli, C., Kärna, A., \& Poskiparta, E. (2011). Counteracting bullying in Finland: The KiVA Program and its effects on different forms of being bullied. International Journal of Behavioural Development, 35, 405-411. http://dx.doi.org/10.1177/0165025411407457

Ševciková, A., \& Šmahel, D. (2009). Online harassment and cyberbullying in the Czech Republic. Zeitschrift für Psychologie/Journal of Psychology, 217(4), 227-229. http://dx.doi.org/10.1027/0044-3409.217.4.227

Sittichai, R., \& Smith, P. K. (2013). Bullying and cyberbullying in Thailand: A review. International Journal of Cyber Society and Education, 6, 31-44. http://dx.doi.org/10.7903/ijcse.1032

Smith, P. K. (2010). Cyberbullying: The European perspective. In J. Mora-Merchán, \& T. Jäger (Eds.), Cyberbullying: A cross-national comparison (pp. 7-19). Landau: Verlag Empirische Padagogik. 
Smith, P. K. (2012). Cyberbullying and cyber aggression. In S. R. Jimerson, A. B. Nickerson, M. J. Mayer, \& M. J. Furlong (Eds.), Handbook of School Violence and School Safety: International Research and Practice (pp. 93-103). New York, NY: Routledge.

Smith, P. K., Mahdavi, J., Carvalho, M., Fisher, S., Russell, S., \& Tippett, N. (2008). Cyberbullying: Its nature and impact in secondary school pupils. Journal of Child Psychology and Psychiatry, 49, 376-385. http://dx.doi.org/10.1111/j.1469-7610.2007.01846.x

Smith, P. K., Pepler, D. K., \& Rigby, K. (Eds.). (2004). Bullying in schools: How Successful Can Interventions be? Cambridge University Press.Thompson, F., Robinson, S., \& Smith, P. K. (2012). Il cyberbullismo nel Regno unito: valutazione di alcune procedure di intervento [An evaluation of some cyberbullying interventions in England]. In M. L. Genta, A. Brighi \& A. Guarini (Eds.), Cyberbullismo: Ricerche e Strategie di Intervento [Cyberbullying research and intervention strategies] (pp.136-153). Milano: Franco Angeli.

Thompson, F., \& Smith, P. K. (2011). The use and effectiveness of anti-bullying strategies in schools. London: DfE.

Tokunaga, R. S. (2010). Following you home from school: A critical review and synthesis of research on cyberbullying victimization. Computers in Human Behavior, 26, 277-287. http://dx.doi.org/10.1016/j.chb.2009.11.014

Ttofi, M. M., \& Farrington, D. P. (2011). Effectiveness of school-based programs to reduce bullying: A systematic and meta-analytic review. Journal of Experimental Criminology, 7, 27-56. http://dx.doi.org/10.1007/s11292-010-9109-1

\section{Copyrights}

Copyright for this article is retained by the author(s), with first publication rights granted to the journal.

This is an open-access article distributed under the terms and conditions of the Creative Commons Attribution license (http://creativecommons.org/licenses/by/3.0/). 